\title{
La ruina de Venezuela no se debe al "socialismo" y la reelección de Maduro
}

Manuel Sutherland

RESUMEN: Más que una transformación socialista (o desarrollista), la economía venezolana vivió una masiva transferencia de renta hacia el capital importador y hacia una casta burocrático-militar que vive a costa de las arcas públicas mediante la sobrevaluación del bolívar y las importaciones fraudulentas para captar divisas a precios preferenciales. Antes que a las revoluciones socialistas clásicas, el proyecto bolivariano se parece a un nacional-populismo militarista.

Palabras-clave: $\quad$ Socialismo. Importaciones. Nacional-populismo. Hiperinflación. Salarios.

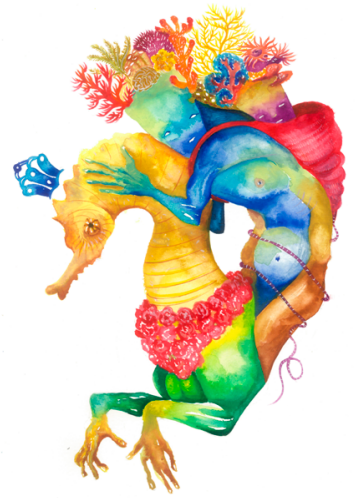

\section{The ruin of \\ Venezuela is not "socialism" and the re-election of Maduro}

\section{Manuel Sutherland}

Economista y Director del Centro de Investigación y Formación Obrera (CIFO).E-mail: alemcifo@gmail.com
ABSTRACT: More than a socialist (or developmentalist) transformation, the Venezuelan economy experienced a massive transfer of income to the importing capital and a transfer to a bureaucratic-military caste that lives at the expense of public coffers through the overvaluation of the currency and fraudulent imports at preferential prices. More than a classic socialist revolution, the Bolivarian project resembles a militaristic national-populism.

Keywords: Socialism. Imports. National-populism. Hyperinflation. Salaries.

RECEBIDO: $28 / 02 / 2018$

APROVADO: $30 / 04 / 2018$ 
RESUMO: Mais do que uma transformação socialista (ou desenvolvimentista), a economia venezuelana experimentou uma enorme transferência de renda para o capital importador e para uma casta burocrático-militar que vive às custas dos cofres públicos através da sobrevalorização da moeda e das importações fraudulentas a preços preferenciais. Mais do que às revoluções socialistas clássicas, o projeto bolivariano assemelha-se a um populismo nacionalista militarista.

Palavras-chave: Socialismo. Importações. Nacional-populismo. Hiperinflação. Salários.

\section{INTRODUCCIÓN}

Pocas personas se atreven a negar que Venezuela sufre la crisis más profunda de su historia. Por quinto año consecutivo, el país presentará la inflación más alta del mundo, estimada en 24.571 \% para el período de mayo de 2017 a mayo de 2018, en mayo de 2018, la inflación del mes alcanzó el 110 \% y la inflación acumulada en 2018 rozó el 1.995 \% (AN: INFLACION..., 2018). De este modo, el país detenta el séptimo mes consecutivo con hiperinflación y ve con estupor cómo los precios suben a diario.

Venezuela posee además un déficit fiscal de dos dígitos (al menos por sexto año consecutivo), el riesgo país más alto del mundo, las reservas internacionales más bajas de los últimos 20 años (menos de 8.900 millones de dólares) y una tremebunda escasez de bienes y servicios esenciales (alimentos y medicinas). El valor del dólar paralelo (que sirve para fijar casi todos los precios de la economía) se ha incrementado en más de $2.500 \%$ en lo que va de 2018, lo cual ha desintegrado por completo el poder adquisitivo de la población (SUTHERLAND, 2015b, 2018).

En ese infausto panorama, Venezuela constituye el "mejor argumento" para las derechas más retrógradas. En cualquier ámbito mediático, aprovechan la situación para asustar a sus compatriotas con preguntas como: “¿Quieren socialismo? iVayan 
a Venezuela y miren la miseria!”, “¿Anhelan un cambio? ¡Miren cómo otra revolución destruye un país próspero!". Sesudos analistas aseveran que las políticas socialistas arruinaron el país y que la solución es una reversión ultraliberal de la revolución.

En estas líneas, quisiéramos mostrar que la política económica bolivariana dista mucho de ser "socialista", e incluso "desarrollista». Lo que a las claras se observa es un proceso de desindustrialización severo en favor de una casta importadora-financiera que, con un discurso enardecido y un clientelismo popular vigoroso, ha acelerado de manera drástica la fase depresiva del ciclo económico capitalista de un proceso nacional de acumulación de capital basado en la apropiación de la renta hidrocarburífera.

Venezuela parecía el sitio perfecto para un cambio de gobierno por la vía electoral. En tal sentido, las elecciones presidenciales pautadas para el 20 de mayo de 2018 se mostraban como un camino factible para un sonoro triunfo de una oposición que supiese aprovechar el bajo nivel de popularidad de un gobierno que enfrenta su quinto año de decrecimiento económico consecutivo. Nunca un gobierno había podido ganar una elección presidencial en medio de una hiperinflación... hasta ahora. Como se sabe, Maduro se reeligió con la ventaja porcentual más grande obtenida por presidente alguno en la joven historia democrática del país. En lo que podríamos llamar crónica de una felpa anunciada, el gobierno triunfa de una manera "inexplicable" y muestra una cohesión realmente prodigiosa en su militancia. Veremos en las líneas finales cómo se gestó esa audaz victoria.

\section{EL CICLO ECONÓMICO Y EL AUGE DE LAS MATERIAS PRIMAS}

El ciclo económico en Venezuela se puede observar en su manifestación más inmediata: las variaciones interanuales del Producto Interno Bruto - PIB. En el gráfico 1 se observan fuertes alteraciones en el ritmo de crecimiento de la economía, con enérgicos ciclos de auge y caída que determinan la volatilidad extrema de la producción, lo que a su vez refleja la fuerte variabilidad de los precios del petróleo. Dados del Banco Central de Venezuela - BCV indican que el "oro negro" constituye alrededor de 95\% de las exportaciones en los años de auge de los precios (2012) y cerca de 65\% en los años 
en que el precio del petróleo es "bajo" (1998), es decir, cuando la renta es exigua y los hidrocarburos ofrecen una ganancia similar a la de una producción industrial "normal".

En el gráfico 1 también puede verse que los ciclos recesivos en la economía empiezan a sucederse a partir de la década de 1980. Los primeros años de ese periodo mostraron la vigorosa influencia de la llamada "crisis de la deuda", que ahogó a muchos países y se manifestó con una intensa caída en los índices de precios de los commodities. En el primer año del periodo bolivariano, el PIB exhibió una fuerte caída, atribuida al bajo precio del petróleo (alrededor de 9 dólares por barril) y, quizás, a la incertidumbre, explicada por el advenimiento de un gobierno nuevo que prometía grandes cambios. Posteriormente, los moderados precios del petróleo se entretejen con un golpe de Estado que derroca por casi dos días al entonces presidente Hugo Chávez, el 11 de abril de 2002. El coup d'État fue acompañado por un macizo paro patronal al que adhirió casi todo el empresariado local. Lo excepcionalmente bajo del PIB del año 2003 obedece más a factores extraeconómicos (diríase políticos) que a razones de índole económica. Lo anterior condujo a un enorme salto en el crecimiento del año 2004 (18\%), que pareció más bien un rebote de la economía.

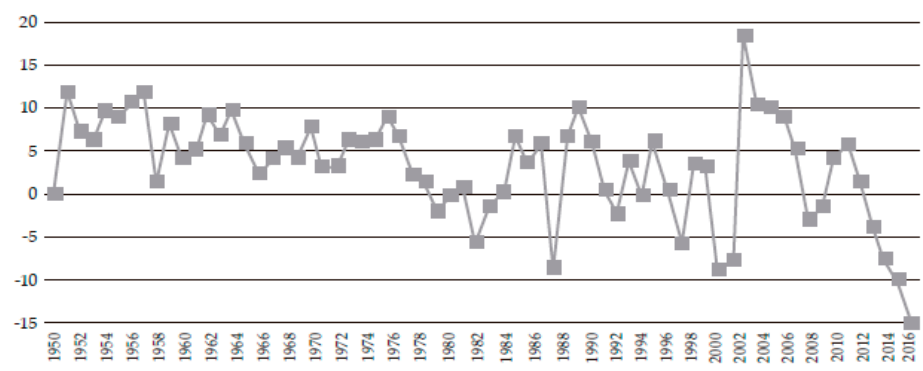

- PIB: variación interanual (en porcentaje)

Nota: el 4 to trimestre de 2015 fue estimado de manera lineal. Se us 6 como PIB de 2016 la estimación del Banco Mundial de 10,1\%, bastante menor a la que ofreció la venezolana Ecoanalítica, que estimó la caída en $16 \%$ (ver www.diarioeltiempo.com.ve/sitio/pib-de-venezuelase-contraera-101-en-2016). Se utilizó como PIB de 2017 la estimación de la Asamblea Nacional disponible en <www.elnuevoherald.com/noticias/mundo/america-latina/venezuela-es/article 193622414.html >.

Fuente: elaboración del autor sobre la base de datos oficiales del BCV: «PIB a precios constantes del año 1997", fecha de consulta: 1/10/2016. 
El gráfico 1 revela también que la economía en 2005-2008 creció a tasas elevadísimas (alrededor de $8 \%$ interanual), impulsada por un fabuloso auge de la renta petrolera, que multiplicó el ingreso por exportaciones más de tres veces. La "edad de oro" económica coincide con los momentos en que el movimiento político bolivariano se muestra más agresivo, empieza a hablar del "socialismo del siglo XXI" en 2005, lanza planes de integración comercial, a ejemplo de la Alianza Bolivariana para los Pueblos de Nuestra América - ALBA, y emprende un proceso de estatizaciones de algunas grandes empresas industriales y de servicios, en rubros como cemento, acero, telecomunicaciones, banca y minería. Pero la abrupta caída de los precios del petróleo a finales de 2008 y a lo largo de 2009, que reflejó los embates de la crisis mundial de 20072008, frenó en seco ambiciones políticas más elevadas. En 2011 se observa una recuperación de la senda de crecimiento económico derivada de un nuevo incremento en los precios del petróleo, que pasan de 35 dólares por barril en 2009 a 120 dólares entre 20112013. Pero en 2014-2015 el precio del petróleo empieza a caer. Sólo el ritmo anualmente incrementado de gastos del gobierno y la hipertrofia en las importaciones hace que precios del petróleo cinco o seis veces más altos que los observados a inicios de la década de 2000 luzcan ahora como "bajos". En esos últimos años empieza la contracción de las importaciones y la caída en la oferta de bienes y servicios, y se hacen visibles los resultados de un proceso de desindustrialización que, en favor de un fervor importador, llegó a subsidiar (con la sobrevaluación del tipo de cambio) 99,9\% de las importaciones de productos como leche líquida, cemento o gasolina, además de obreros (chinos) para construir viviendas.

La expansión rentística duró un tiempo excepcionalmente largo y en ella se profundizaron los males que traen aparejados los estallidos repentinos en el ingreso petrolero. La industria y el agro se redujeron con la hoz de un tipo de cambio groseramente sobrevaluado (KORNBLIHTT; DACHEVSKY, 2017). Lo importado resultó extremadamente barato y se desincentivó cualquier esfuerzo productivo industrial o agrícola. Esta política nada tiene que ver con el "socialismo real", ni tampoco con el desarrollo de fuerzas productivas pregonado por Karl Marx. Estado y empresarios se 
volcaron a la faena de exportar la renta petrolera sobre la base de importaciones recrecidas y fuertemente subsidiadas, la fuga de capitales se disparó y se expandió un endeudamiento externo a onerosas tasas de interés (para exportar la renta futura).

\section{CÓMO SE LICUÓ LA RENTA PETROLERA EN IMPORTACIONES}

La carestía de bienes básicos también fue consecuencia de una vigorosa exportación de capitales que restó capacidad de inversión productiva, gracias a una enorme sobrevaluación de la moneda. Esta política monetaria no es más que una inconcebible transferencia de renta petrolera desde el Estado "socialista" hacia los importadores, quienes reciben muchos más dólares de los que deberían absorber por los bolívares que desembolsan. Eso significa que cada vez que el gobierno vendía 10 dólares les estaba regalando (al menos) 9,5 dólares. Esta lucrativa transferencia de renta al sector privado es el negocio más oneroso y lesivo a la nación que se pueda imaginar. Pero peor aún ha sido que las supuestas mercancías compradas con ese dólar "de regalo" han sido en gran parte fraudes masivos, ya que la mayoría de ellas nunca entró en el país.

En el gráfico 2 se ve con más detalle que el enorme auge exportador de Venezuela, facilitado por la multiplicación del precio del petróleo por más de diez, se ha visto acompañado por un voraz auge importador. Las importaciones, que en 2003 apenas rozaban los 14.000 millones de dólares (valor CIF), alcanzaron en 2012 los 80.000 millones (INSTITUTO NACIONAL DE ESTADÍSTICAS, 2017), y aunque 70\% de estas importaciones está supuestamente orientado a la inversión productiva, esto no se vio reflejado en un aumento correlativo de la producción. El aumento de 457\% en las importaciones (valor CIF) para el periodo 2003-2012 refleja que el ritmo en la importación fue a todas luces exagerado y sin ninguna perspectiva de ahorro ante una posible declinación del ciclo económico derivado de una esperada caída en los precios del petróleo. De hecho, el aumento de las exportaciones para ese mismo periodo fue de $257 \%$, mucho menor al aumento de las importaciones. 
Gráfico 2

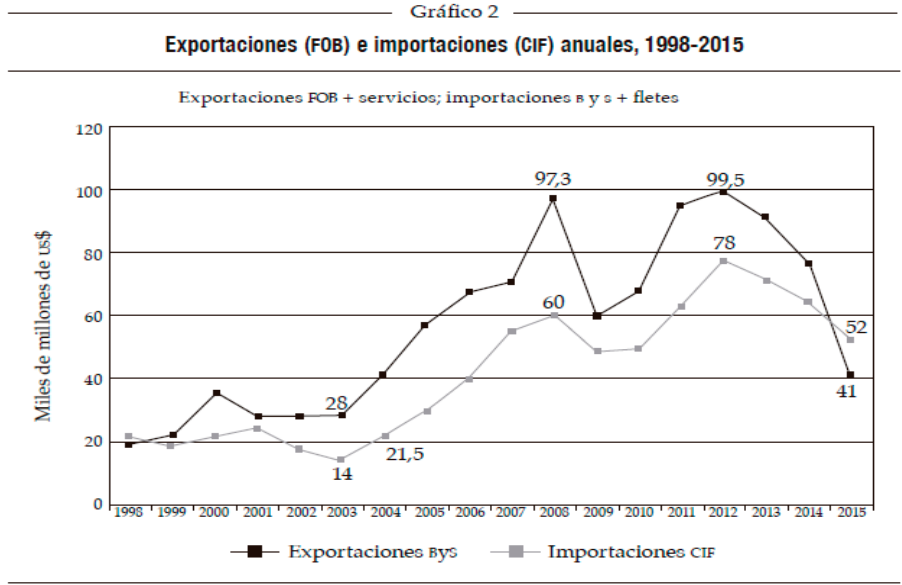

Nota: para el año 2015 se promedió el último trimestre con los tres anteriores, ya que aún no había sido publicado.

Fuente: elaboración del autor sobre la base de datos oficiales del BCV, en su cuenta «Valor FOB de

las exportaciones y valores CIF de las importaciones".

Si se observan los términos de intercambio aplicados a las exportaciones no petroleras venezolanas, se puede apreciar que el precio pagado por cada kilogramo exportado de mercancías ha subido en apenas 11\% (1998-2014), lo cual no justifica un aumento tan fuerte en los precios de las importaciones (INE, 2017). Lejos de favorecer a la industria nacional, estatal o privada, el gobierno se ha volcado a resolver necesidades diversas a fuerza de importaciones masivas. Por ejemplo, el sector público ha aumentado en 1.033\% las importaciones entre 2003 y 2013, con incrementos interanuales que llegaron a alcanzar el 51\% (2007), en lugar de invertir en la creación de empresas propias.

\section{EL FRAUDE EN LA IMPORTACIÓN}

Las importaciones fraudulentas son una parte importante de la exportación de la renta petrolera. En otro trabajo, hemos explicado ese mecanismo (SUTHERLAND, 2015a). Aquí sólo haremos una sinopsis enfocada en un rubro esencial: la carne. El aumento de la importación (valor FOB) de carnes para el periodo que va entre 2003 (inicio del control de cambio) y 2013 fue de $17.810 \%$. Sí, más de $17.000 \%$. Lo "asombroso" es que el consumo nacional 
promedio de carne disminuyó 22\% para ese mismo periodo, como ya lo explicamos en un trabajo que dedicamos exclusivamente a la importación de productos cárnicos (SUTHERLAND, 2014). De sólo importar 10 millones de dólares anuales, se pasó a importar más de 1.700 millones de dólares. Ni hablar de que hace meses que no se halla carne de manera regular en los supermercados. Como complemento de ello, se puede ver que entre 1998 y 2013 el incremento en la importación (valor FOB) de animales vivos fue de $2.280 \%$. Para ese mismo año, el valor FOB de la exportación de animales vivos descendió 99,78\% (sólo 4.300 dólares) (NEUMAN; TORRES, 2015). Son famosas las denuncias de importaciones de "fabulosas" máquinas de cortar césped de 12.000 dólares y de armatostes para procesar pollos de 2 millones de dólares: cuando la gendarmería aduanal revisó el contenedor, sólo encontró herramientas oxidadas (NEUMAN; TORRES, 2015). La reconocida empresa de consultoría Ecoanalítica calculó que de 2003 a 2012 se robaron 69.500 millones de dólares mediante importaciones fraudulentas. Exportadores de la zona de libre comercio de Panamá "facturaron" 1.400 millones de dólares en envíos a Venezuela; sin embargo, funcionarios panameños aseguran que, de esa cantidad, 937 millones fueron fraudulentos: las compañías facturaban productos inexistentes. En otro de los casos documentados, una compañía que importaba equipos agrícolas declaró el costo de una máquina para desgranar mazorcas en 477.750 dólares, cuando su verdadero precio es 2.900 dólares (NEUMAN; TORRES, 2015).

\section{PARA SINTETIZAR (AÚN MÁS) LAS POLÍTICAS ECONÓMICAS LEJANAS AL SOCIALISMO}

De forma muy breve, se podría aseverar que:

1. Las estatizaciones han sido, por lo general, provechosos negocios para la burguesía local. En la gran mayoría de ellas se ha pagado mucho por empresas técnicamente obsoletas. Un ejemplo significativ6.o es la nacionalización del Banco de Venezuela: por el $51 \%$ de las acciones que compró, el Estado pagó 1.050 millones de dólares, a pesar de que el banco había sido adquirido por el 
Grupo Santander (93\% del paquete accionario) en menos de 300 millones de dólares.

2. La muy necesaria "reforma tributaria" sigue pendiente. Según la Comisión Económica para América Latina y el Caribe (Cepal), los países que mostraron los mayores incrementos desde 1990 en sus promedios de ingresos fiscales sobre el PIB fueron Bolivia $(20,6$ puntos porcentuales) y Argentina $(18,8)$, mientras que Venezuela registró un descenso de 4,5 puntos porcentuales (MONTES, 2015).

3. Menos "socialista" ha sido la fragmentación del capital en decenas de instituciones financieras de escaso capital y notable ineficiencia. El fraccionamiento de la banca estatal ha sido acompañado por una política de créditos baratos, que choca con la delirante idea de la "guerra económica". Decimos esto porque si el gobierno asevera que los empresarios sabotean la economía produciendo menos, vendiendo caro y escondiendo sus productos, es absurdo y contradictorio que el gobierno financie a esos empresarios con millonarios créditos a tasa de interés negativa. ¿Cómo justificar la dádiva munificente a quienes supuestamente llevan adelante la "guerra económica"?

Ejemplos de esos "obsequios" (además del tipo de cambio preferencial) hay muchos. Recientemente, el vicepresidente Tareck El Aissami detalló: "La meta es inyectarle en el primer semestre de 2018 al sector privado 10 billones de bolívares en créditos, lo que representará casi un tercio del presupuesto nacional" (CRESPO, 2018) También le prestan dólares a la burguesía: por ejemplo, la empresa Nestlé recibió un crédito de 9 millones de dólares y Ron Santa Teresa, 4 millones de dólares (ESTAS..., 2017). Hace poco, Maduro aprobó en el cierre de la Expo Venezuela Potencia otro crédito por 25 millones de dólares a distintas empresas venezolanas (ESTAS..., 2017).

4. El PIB industrial registró un notable incremento (2004-2008), para luego decrecer a niveles por debajo del de 1997, situación preocupante y que se podría considerar paradójica a simple vista, ya que en los años de crecimiento elevado (2004-2008) la importación de maquinaria y equipos industriales (formación bruta de capital fijo) se quintuplicó. Un proceso de industrialización estatal masivo y a gran escala es la base de todo gobierno que se precie 
como desarrollista o socialista, pero en Venezuela se hizo lo contrario.

Muchas de las series de datos oficiales de producción industrial física disponibles (a febrero de 2018) terminan en 2011. Si se analiza con cifras recientes la producción de automóviles, se ve que el retroceso ha sido extraordinario. Entre 2007 y 2015, esta producción se ha desplomado en un impresionante 89\%; el guarismo de 2015 es casi tan bajo como el registro de 1962, cuando nació formalmente la industria automotriz y se ensamblaron 10.000 vehículos. Desde 2007, año en que se ensamblaron 172.418 unidades, la industria automotriz ha caído en picada: en 2015 se contrajo a su peor nivel en 53 años y ensambló apenas 18.300 unidades (DENIZ, 2016). Según datos de la Cámara Automotriz de Venezuela y de la Federación Venezolana de Autopartes, el ensamblaje de vehículos cayó hasta 2.694 unidades, 83\% menos que en los mismos 11 meses de 2015 (FABRICANTES VENEZOLANOS DE PRODUCTOS AUTOMOTORES, 2016).

\section{SALARIOS, DEPAUPERACIÓN Y PERSPECTIVAS}

En apretado sumario, se ha visto que no se trata del fracaso de medidas económicas que emanan de los textos de Marx o de la Revolución Rusa. En algunos elementos puntuales, se ha observado que la política económica bolivariana no tiene nada que ver con un cambio revolucionario anticapitalista ni con una metamorfosis de las relaciones sociales de producción. El proceso bolivariano ha sido más bien una variante de las políticas económicas que derivan del llamado "rentismo petrolero", que ya se habían experimentado en el primer gobierno de Carlos Andrés Pérez (19741979). El componente ideológico y algunos discursos de talante antiimperialista y antiempresarial confunden a la mayoría de los analistas que estudian las alocuciones de los presidentes y no sus políticas concretas.

Aunque el gobierno bolivariano expandió el gasto social, estatizó empresas, desarrolló políticas de transferencias directas a los más pobres y otorgó subsidios enormes en los servicios públicos, la centralidad de su política económica no fue más que la 
continuación de la apropiación radicícola de la renta petrolera y de su derro1 che, con el agravamiento de la consolidación de políticas de "control" que sólo aceleraron los procesos de destrucción del agro, la industria y el comercio en favor del enriquecimiento del capital importador-financiero y el engorde de una casta militar-burocrática hipercorrupta que saquea a manos llenas a la nación, hasta empobrecerla a niveles nunca antes vistos en estas latitudes.

El último gráfico que se presenta revela el resultado directo de la política de expolio de la renta a través de la sobrevaluación de la moneda, la emisión de dinero inorgánico (el gobierno incrementó la base monetaria en más de $2.500 .000 \%$ entre 1999 y 2018) como política útil para sostener un gasto público utilizado de manera clientelar y anarquizada. El gráfico 3 refleja la caída en 83\%, entre 2006-2017, de la remuneración mínima mensual (salario más bono de alimentación) que recibe la clase trabajadora.

La izquierda mundial no tiene por qué acallar sus críticas ni forzar defensas estrafalarias y atávicas en aras de "no mimetizarse con la derecha" en un análisis riguroso del proceso nacional de acumulación de capital en Venezuela. La izquierda debe criticar a los "progresismos" con la misma sagacidad y agudeza que aplica a regímenes abiertamente antiobreros y derechistas. No tiene por qué ignorar la centralidad de los problemas que acaecen en esos países, sino que debe colaborar con ágiles propuestas sin hesitar, y ello pasa por analizarlos objetivamente y criticarlos con conocimiento dialéctico, no con catilinarias. Si se hundió el Titanic, no hay que negar el hecho concreto del naufragio en aras de ser solidarios y antiimperialistas. 
Gráfico 3

Caída en remuneración obrera (salario real más bono de alimentación CT), 2006-2017

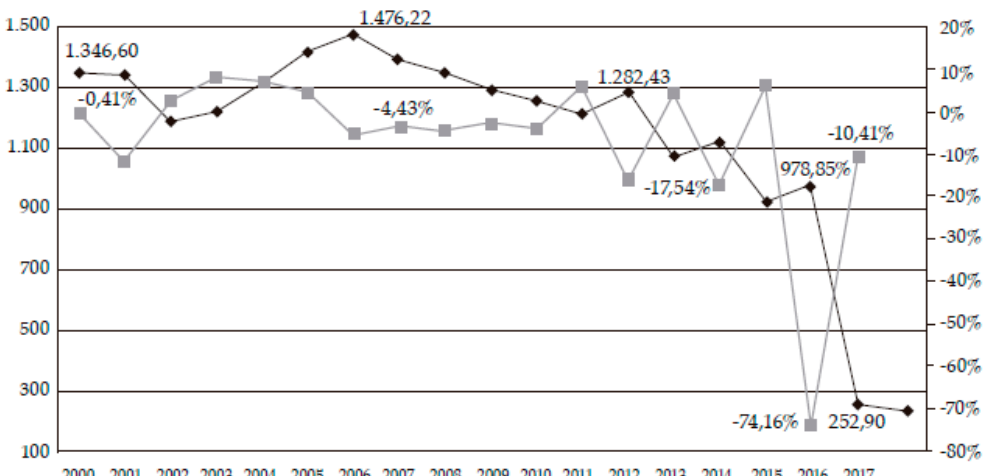

Indice de salario real

- Variaciones interanuales

Fuente: BCV: Índice de remuneraciones; histórico de salarios mínimos en Notilogía. Se tomó en cuenta el salario más el bono de alimentación, a pesar de que solo se entrega a quienes trabajan en situación de formalidad, alrededor de $50 \%$ de la población obrera. Año base 2000. INPC (20082015) e IPC (2000-2007). Para la inflación de 2016, se utilizó el guarismo conocido de $274 \%$ que el BCV adjuntó en un informe al Fondo Monetario Internacional (FMI): <www.finanzasdigital. com/2017/04/ bcv-reporto-al-fmi-una-inflacion-274-2016/>. Para 2017 se utilizó la cifra de inflación que arroja la Asamblea Nacional (Comisión de Finanzas): <www.eluniversal.com/noticias/ economia/inflacion-venezuela-durante-2017-cerro-2616_683471>.

\section{VENEZUELA: LUMPENCAPITALISMO O CAPITALISMO MALANDRO'}

Hemos comentado en otros escritos (SUTHERLAND, 2018) el por qué consideramos que el chavismo nada tiene que ver con un programa socialista de cambio estructural, desarrollista o incluso nacionalista in stricto sensu. De alguna manera se ha disertado en relación a que el proyecto bolivariano es una especie de nacional populismo militarista, cuya determinación estriba en el control de

1 Malandro es un término polisémico que en algunos países de Sudamérica se asocia a la delincuencia violenta de origen popular desplegada en diversas formas. El malandro antepone su egoísta anhelo de poder y dinero, al bien común, en ese sentido agrede fundamentalmente a la clase social de la cual originalmente deviene (MORENO, 2012). Su interés no solía ser político.... 
la renta petrolera y la posterior distribución de la misma entre capitalistas, burócratas y militares afectos al gobierno (SUTHERLAND, 2016). Sin embargo, las formas que reviste el proceso nacional de acumulación capitalista en Venezuela parecen representar de manera dramática a una especie de lumpencapitalismo o capitalismo malandro relativamente infrecuente en repúblicas de vieja data.

Un estudio minucioso de la economía local nos muestra la mar de sin sentidos en las más diversas áreas de política económica. Las críticas que se hacen desde la extrema derecha hasta la extrema izquierda coinciden en que la situación actual es inaudita por el grado de indolencia estatal. La abulia generalizada del gobierno ante la crisis y su olímpica negativa a realizar acciones para amainar sus efectos resultan en un enigma para todos los actores políticos que se preguntan por qué no se toman algunas medidas simples para revertir estas resultas. ¿Por qué no abandonan prácticas económicas inútiles que ahorcan a las empresas privadas y públicas? En otros escritos hemos tratado de dar algunas respuestas desde el ámbito macroeconómico (SUTHERLAND, 2015a, 2017b). En esta ocasión se podría hablar del ámbito microeconómico de la crisis y desde el acontecer diario de la clase obrera.

\section{LUMPENCAPITALISMO EN PLENO DESARROLLO...}

Un obrero sale en la mañana a su casa y no encuentra transporte público terrestre. Las unidades del estatal Metrobus están casi todas inoperativas por falta de repuestos. Entra al metro y se encuentra que los vagones vienen atestados, las escaleras mecánicas no sirven, hay fuertes retrasos y en los furgones pululan ladrones y mendigos. Al salir del metro se encuentra un robo ponzoñoso, con golpes y gritos. La policía no aparece y la víctima sabe que es inútil denunciar. Llega al trabajo y ve que su salario semanal alcanza para comprar sólo dos tomates y que ahora necesita trabajar un mes y dos días para comprar un Big Mac, que un obrero en Chile compra con 36 minutos de labor y que su par de Hong Kong adquiere en apenas en 12 minutos de faena. Piensa en comprar un pollo entero congelado para hornear en casa. 
Inmediatamente recuerda que requiere de dos meses de salario (más bono de alimentación) para adquirir la jugosa ave.

Nuestro obrero sale del trabajo y hay camiones de carga que hacen de transporte. Ahí se viaja de pie y entre cientos de personas. Para tomar un camión hay una cola infinita y se requiere dinero en efectivo - que con suerte pudo extraer del cajero luego de hacer una fila de varias horas, porque hay una dramática escasez de efectivo. Al llegar a su casa se encuentra con que aún no ha llegado la luz eléctrica. Serios apagones le dañaron la televisión, y por ello trata de escuchar la radio, donde se anuncia que el racionamiento de agua será más severo. Hidrocapital le suministrará el vital líquido sólo los miércoles y los sábados. Se siente afortunado porque a otros les llega una vez al mes. Se asoma a la ventana y observa que la lluvia colapsó las alcantarillas. Las aguas residuales anegan la calzada y el olor es nauseabundo. Come un mango y quiere llamar a su ex, pero recuerda que ella está viajando a Chile en autobús desde Caracas para trabajar en "lo que sea". El mismo derrotero tomó su prima, su sobrino y varios compañeros de la universidad en la que se cansaron de esperar a un profesor que les impartiera la única materia que les faltaba para obtener un título que difícilmente será reconocido fuera del país. Mira su manchada alfombra y reza para que su hermano que trabaja en Brasil le envíe algún dinero, pero no sabe cómo, pues el gobierno bloqueó las formas normales de recepción de divisas. ${ }^{2}$ Se duerme pensando en que no tiene saldo en el teléfono y no hay tarjetas telefónicas en los kioscos. Recuerda que la página web del Banco de Venezuela más nunca le abrió y no sabe ni cuánto dinero le queda ahí. Se ríe a medio camino y cree que ha tenido días peores...

Ahora, la pregunta sería: ¿cómo puede funcionar así un país medianamente civilizado? ¿Cómo pueden colapsar tantas cosas que antes marchaban? La respuesta es que el gobierno no está interesado en atender a ninguna de las problemáticas anteriores. Políticamente afirma que todas las dificultades son responsabilidad de la ubicua "guerra económica". Comentan que Trump

2 La apertura formal para recibir remesas a un tipo de cambio similar al tipo de cambio paralelo se hizo a finales de junio de este año. 
sabotea el ingreso de medicinas y alimentos al país y que además organiza a los empresarios para subir los precios adrede e inducir hiperinflación. Ideológicamente dice que la "crisis" no es tal, sino que es parte de una guerra de quinta generación que el inmarcesible "imperialismo" aplica a Venezuela por ser el ejemplo de rebelión mundial más exitoso. Económicamente no realiza ninguna medida concreta porque el asunto no es económico, sino político, la economía no va bien por culpa del imperio. Por ejemplo, el Ministro de Energía Eléctrica asegura que los apagones se deben a sabotajes que se realizan con iguanas y varas de bambú (MOTTA..., 2017). En la oficialista gobernación del Zulia fueron más ingeniosos y aseveran que los recientes apagones se deben a que en dicho estado el sol está muy cerca de la tierra (GOBERNACIÓN..., 2018).

El gobierno no presta cuidado a ninguna dificultad cotidiana porque realmente no amerita del buen andar de la economía para generar recursos necesarios para su financiamiento. Es decir, el gobierno simplemente incrementa la Base Monetaria a través de una bicicleta financiera en la cual endeuda a PDVSA (ARMAS, 2016) a través de infinitos pagarés que nunca paga, y así "crea" dinero sin ninguna base productiva de respaldo. El gobierno ha incrementado los préstamos del BCV a PDVSA en 62\% en menos de 3 años. Ese provento lo gasta sin el más mínimo control y recato. No requiere de créditos adicionales aprobados por la Asamblea Nacional, ni de endeudamiento interno privado, ni de reforma tributaria alguna. De hecho, se dio el lujo de prorrogar por dos meses el cobro del impuesto sobre la renta en plena hiperinflación. No sólo eso, también dijo que con declarar bastaba, y que se podía prorratear el pago en varios meses.

El contrato social por el cual el Estado brinda servicios a cambio de impuestos se rompe. El Estado no sólo es dueño omnímodo de la munificente renta petrolera, sino que tiene el monopolio de la creación artificial de dinero. Más aún, el dinero que emite ni siquiera lo imprime. Según dados del BCV, la otrora relación de dinero físico sobre base monetaria rondaba el 37\% en 2009, para 2018 esta relación es apenas 4\%, es decir, hacen falta 9 veces más billetes y monedas de los que el gobierno imprimió. Obviamente, el gobierno jamás admite un error. Por ello, el culpable de la escasez 
de dinero es el contrabando de dinero venezolano hacia Colombia y Brasil (QUÉ HACEN ..., 2016).

El gobierno realiza operaciones digitales donde "mágicamente" aparecen cifras mil millonarias en diversas cuentas, con deudas que jamás se cobrará a sí mismo. Este dinero rematadamente inorgánico, ese capital ficticio (Marx dixit) que lanza a la calle se encuentra con una oferta de bienes cada vez menor, por el cierre de empresas, la caída en la producción, el desplome de las importaciones y el contrabando de extracción. Esta demanda "fantástica" encuentra menos oferta de bienes y el resultado es la trepidante hiperinflación anualizada (mayo 2017 a mayo 2018), que cabalga por encima del 24 mil por ciento. La destrucción correlativa que trae aparejado el incremento sideral en los precios no importa. Con decir que no hay explicación "lógica" para el crecimiento de los precios, les basta. De hecho, sus personeros y acólitos más íntimos, tienen la orden de no hablar de hiperinflación, sino de hiperespeculación inducida por una página web que reporta las variaciones diarias del precio del dólar paralelo, el argentino Marco Teruggi (2016) y el español Alfredo Serrano, se han hecho profesionales en disertar sobre la inflación inducida. La economista Pasculina Cursio (2018) incluso se atrevió a decir que la hiperinflación en la República de Weimar fue inducida gracias a un ataque imperialista que manipuló el tipo de cambio a través de los reportes del New York Times. Por esos desternillantes aportes, el gobierno la premió nombrándola para la Junta Directiva del Banco Central de Venezuela, a pesar de que ella ni siquiera ha trabajado en esa institución.

La vorágine en el incremento de los precios se marida con un par de astutas tácticas gubernamentales: (1) el hipercontrol (que nada controla) en la producción y distribución de bienes y (2) los chantajes que, ley en mano, se desarrollan gracias a la imposibilidad práctica de cumplir con las legislaciones que fungen como trabas insuperables a la acumulación de capital privado y público.

Sabiendo que las promesas de controlar la producción de zanahorias desde el conuco hasta la nevera citadina son ridículamente irrealizables, el entramado legal tiene una función mucho más sórdida, que radica en la presión y asfixia jurídica que aplica a 
la población. El complejísimo enjambre de leyes y normas inverosímiles de imposible cumplimiento tiene a la población completamente a merced de una jauría de fiscales, policías y militares que utilizan estas delirantes normas para extorsionar a quien alguna actividad económica intenta emprender. Las legislaciones son abiertamente inservibles y rayan en un absurdo kafkiano, lo cual hace que todos las infrinjan. Ahora, la idea del lumpencapitalismo no es impedir que se quebranten estas pautas; la intención es extorsionar a quienes incurren en ellas, es decir, "vacunar" a miles de unidades económicas y tener a toda la población en ascuas, ya que con la aplicación rigurosa de esas leyes podrían encarcelar a cualquier persona por maniobras completamente normales en otros países.

La ley de precios justos (y eternos), la ley de precios acordados, la ley contra el acaparamiento, la ley contra el ilícito cambiario, la ley de legitimación de capitales y un sinfín de reglamentos menores correlativos, facultan a casi cualquier agente a construir un caso que puede fácilmente llevar a la cárcel por 10 años. Moralmente convierte a todos en infractores, en delincuentes reincidentes que el gobierno perdona (cuando pide una coima). Delincuentes que de nada pueden reclamar. En el lumpencapitalismo todos son convertidos en malhechores y cómplices.

\section{EL 20 DE MAYO: ELECCIONES EN EL CLÍMAX DEL LUMPENCAPITALISMO}

El 20 mayo se iba a elecciones por enésima vez. Desde 1999 se convocan elecciones una tras otra sin descanso. En este mayo estival, la Asamblea Nacional Constituyente - ANC había decidido que las presidenciales debían realizarse con unos seis meses de adelanto, en aras de favorecer a la estabilidad política. Nadie sabe por qué la ANC se arroga la facultad de decir cuándo deben ser las elecciones. Y nadie sabe por qué las ANC legisla, elabora normas y decretos, cuando se supone que debería redactar una nueva Constitución (cosa que ni siquiera discute).

El llamado a elecciones tomó a la oposición por sorpresa, aunque ésta había insistido en adelantar la refriega electoral 
varias veces. Algunos de sus partidos, los más grandes (Primero Justicia, Acción Democrática y Voluntad Popular), habían sido inhabilitados por no participar en las elecciones municipales anteriores (SUTHERLAND, 2017a). Dicha inhabilitación fue argumentada bajo un manto interpretativo de normas en las cuales se indica que los partidos que no participaron en la anterior contienda deben renovarse a través de un peliagudo proceso de validación de firmas de su militancia a nivel nacional. Estos partidos, según el Consejo Nacional Electoral, no lo lograron. Así las cosas, sólo algunos pocos partidos opositores pequeños pudieron ser inscritos en la cruzada del 20 de mayo. Poco antes, el Tribunal Supremo de Justicia había eliminado la tarjeta de la Mesa de la Unidad Democrática - MUD, la del logo de la manito, por consideraciones tan rebuscadas como risibles, ya que la principal razón argüida fue que la conformación de la MUD obedece a la agrupación de diversas organizaciones políticas ya renovadas y otras pendientes de renovación, y dicho carácter de agrupación es contrario a la prohibición de la doble militancia (PUCHE, 2018).

El único candidato opositor con cierta posibilidad de triunfo era Henry Falcón, quien venía de las filas del chavismo (hasta 2011) y había hecho carrera como Alcalde y Gobernador en el Estado Lara. Aunque el grueso de la oposición de derecha considera al gobierno bolivariano como una dictadura "fascista" peor que la de Videla y Pinochet juntas, tomaron la decisión firme de abstenerse porque no había condiciones electorales ideales para poder participar. No sólo eso: dedicaron un esfuerzo notable a combatir a la candidatura de Falcón, llenando las redes sociales de vituperios y filípicas contra él. Con especial denuedo trabajaron en generar abstención en la base opositora y aseveraron que el sistema electoral es completamente fraudulento y que el voto no es secreto, a pesar de que ellos habían ganado (y con amplio margen) en las elecciones a la Asamblea Nacional en el cercano 2015.

Aunque el Falcón y su grupo certificó que las condiciones electorales de 2018 eran iguales (o mejores) a las de 2015 y que había que defender el voto a través de las 21 auditorías que tiene el proceso de conteo y totalización digital, la oposición insistió en que la táctica correcta era deslegitimar a Maduro creando una gran 
abstención que desnudara lo ilegal que había sido la reyerta electoral. Con esa deslumbrante maniobra Maduro quedaría desprestigiado ante el mundo y perdería la "legitimidad de origen". Eso empujaría a la gente a la calle a realizar protestas masivas y haría que la comunidad internacional elaborase sanciones y presiones durísimas en contra del país. Ello obligaría a Maduro a ofrecer condiciones electorales ideales o a renunciar.

Para nadie es un secreto que las elecciones en el cénit del lumpencapitalismo no pueden desarrollarse en un clima que no sea de ventajismo sicalíptico, pornográfico. El presidente hizo lo que siempre hace el chavismo: grandes concentraciones de personas en avenidas aderezadas con tarimas y estruendosos conjuntos musicales de reggaetón. Con gran dedicación los punteros del gobierno templaron a la tan subestimada triada populista clientelar (SUTHERLAND, 2017a) con que ganaron las últimas elecciones con amplio margen, y que se puede resumir en:

1. La engrasada maquinaria electoral del PSUV en franco maridaje con la distribución de prebendas clientelares que van desde bolsas de comidas, un tesoro en medio de la hiperinflación y la escasez, casas, automóviles y electrodomésticos.

2. La aceitadísima maquinita de imprimir dinero inorgánico (el aumento en la base monetaria emitida por Banco Central de Venezuela para el período de mayo de 2016 a mayo de 2018 fue de $39.414 \%$, es decir, un aumento de más de 390 veces en dos años).

3. La postergación del ajuste macroeconómico y el mantenimiento de subsidios del 99,99\% al precio de la gasolina, transporte, agua etc., que hoy ya son gratuitos (un huevo de gallina equivale a 100 mil litros de gasolina de 91 octanos).

\section{UN PASO MÁS FRONTAL EN EL POPULISMO CLIENTELAR: UN BONO POR VOTAR}

"Todos los que tengan su carnet de la patria y ejerzan su derecho y su deber al voto, van a tener un premio de la patria, legal constitucional, dando y dando (...) el premio por votar el 20 de mayo."

(Nicolás Maduro) 
A la triada normal del lumpen capitalismo, el gobierno le agregó la promesa de pagar un bono en metálico (equivalente a 4 salarios, con su bono de alimentación respectivo) a quienes salieran a votar y escanearan su carné de la patria en los polémicos puntos rojos, que no son más que toldos donde partidarios del chavismo van chequeando los votos de sus acólitos. Nunca antes la "compra de votos" se había hecho de una forma tan palurda y sin el menor de los disfraces. La cuestión era: un voto es igual a un bono, dando y dando. En la avenida Bolívar de Charallave, en el estado Miranda, en acto transmitido en vivo por Venezolana de Televisión (ROMERO, 2018), Maduro no sólo repitió la oferta del bono sino que aseguró dicho pago con su palabra. ${ }^{3}$ El asunto fue tan desvergonzado y chocarrero que tuvo que salir el muy chavista Consejo Nacional Elector - CNE a decir que es completamente ilegal ofrecer dinero a cambio de votos. La presidente del CNE, Tibisay Lucena, informó que "No se va a realizar pago de bono ni incentivo monetario en los puntos [rojos]" (URDANETA, 2018).

Capítulo aparte merece el trabajo de miles de "empleados públicos" que no son más que activos militantes del chavismo encargados de buscar votos, llenar concentraciones, organizar marchas y ver quien está o no a favor del gobierno en sus políticas. Estos "punteros" no realizan ninguna labor burocrática, están completamente al servicio de asegurar votos a través de la difusión de la propaganda oficial y de la distribución de las prebendas que dimana el erario público.

El resultado no fue nada sorprendente, con una oposición (MUD y Frente Amplia Venezuela Libre - FAVL) completamente volcadas en contra de Falcón y llamando ardientemente a no votar hasta tener condiciones electorales ideales (en el medio de una "dictadura fascista", como ellos la llaman). Maduro corrió prácticamente solo. Aunque hubo la abstención más alta de la historia en elecciones presidenciales (54\%) (CNE, 2018), es fácilmente argumentable que en otros países la abstención es mucho mayor y que ningún gobierno se resiente de ello.

3 Obviamente, el pago del bono nunca se hizo. 
Maduro obtuvo la victoria más holgada que se haya visto en elecciones presidenciales en la historia del país. El "conductor de victorias", como lo llaman en la televisión estatal, obtuvo la bicoca de $67,84 \%$, dejando a Henry Falcón con un escuálido 20,93\% (a pesar de toda la campaña de ataques que le hizo la MUD y el FAVL, parece bastante). El presidente reelegido obtuvo 6.245.862 votos, más o menos el 30\% del padrón electoral. Esta cifra, que luce pequeña, es insólita si se analiza que el país atraviesa la peor crisis de su historia. El "pacificador", como lo llama la radio estatal, quizás pase a la historia como el único presidente que triunfa en unas elecciones en el medio de una hiperinflación. A todas luces el nuevo triunfo del chavismo muestra paisajes muy áridos para la oposición de izquierda y de derecha.

\section{PERSPECTIVAS ECONÓMICAS Y POLÍTICAS DEL CHAVISMO AL CORTO PLAZO}

La nueva victoria de Maduro iba a ser efímera, según la ultraderecha. Según ellos, y según buena parte de la derecha abstencionista, la victoria de la abstención traería el ostracismo de Maduro y una escalada de sanciones y bloqueos económicos bestiales. En sus quimeras imaginaron un lunes 21 de mayo lleno de protestas en el medio de un fervor jubiloso del abstencionismo activo que iba a hacerse de la calzada y expulsar rápidamente al tirano a fuerza de marchas, mítines y encendidas proclamas en redes sociales. Por Twitter convocaron a protestas frente a la OEA y llamaron a calentar la calle. Quienes esperaban con algarabía otra espiral de protestas y enfrentamientos callejeros contra la policía. El lunes sufrieron una dura desilusión al ver que prácticamente nadie salió a protestar y que la mayoría de los opositores estaba sumergida en una depresión política atroz e inexorable.

Los dirigentes de la extrema derecha, los más furibundamente abstencionistas, se apresuraron a auto elogiarse por el histórico triunfo de la "abstención" que sin dudas destronaría a Maduro. En algunas de sus redes sociales soltaron perlas de este estilo, del economista Ángel García Banchs (2018, não paginado): 
Con la abstención se ha deslegitimado internacionalmente al narco régimen. Próximo paso deslegitimar a la MUD. Luego nombrar Dictadura republicana (Junta de gobierno) y finalmente intervenir militarmente Venezuela por meses para tomar el poder y hacer profilaxis.

Muy al contrario de su base social, completamente abatida tras veinte años de estar muy cerca de destronar a los tiranos, los opositores de ultraderecha aseguraron que estaban cerca de la intervención militar de EEUU, de lograr que Colombia invadiera o de lanzar un "Noriegazo" o "Ghadaffizaso". Comentaban que operaciones quirúrgicas de extracción militar se estaban cocinando para poner fin a lo que ellos intitulan "narcocastrismo". El 21 de mayo y los días subsiguientes demostraron que no parece haber ánimo en sus bases para otras protestas con enfrentamientos callejeros, guarimbaso ${ }^{4}$ expediciones que terminen en trifulcas violentas con la Guardia Nacional. Las marchas pacíficas tampoco atrajeron a una base opositora extenuada de un sinfín de fracasos que cada día les hace desarrollar mayor desconfianza y animadversión en contra de sus líderes opositores.

La base chavista no festejó. Partidos pequeños de izquierda, que apoyan (literalmente) al gobierno sin pedir nada a cambio, se han mostrado críticos con las políticas del gobierno y ahorraron la mayoría de las usuales proclamas grandilocuentes al estilo: "Hemos hecho historia derrotando al imperialismo". Más bien dijeron cosas como: "Es hora ya de hacer cambios, no de celebrar." En el PSUV aparecieron varios escritos críticos. Aunque no es exactamente autocrítica, varios intelectuales chavistas, como Luís Britto, Néstor Francia, Earle Herrera o Roberto Hernández Montoya, levantaron su voz pidiendo "cambios" de manera abstracta, tímida, pero interesante para un partido-gobierno-Estado muy sensible a la crítica. Incluso los "guerreros económicos" alzaron su voz para

4 Es una suerte de piquete o corte de ruta, que viene aparejado con quema de diversos elementos y que tiene como meta impedir el libre tránsito. En el medio del capitalismo lumpen la guarimba lleva en muchas ocasiones el aderezo de atracos a transeúntes, mendicidad violenta, vacunas, extorsiones y amenazas a conductores que no quieran "colaborar" por las buenas con la causa libertaria. 
exigir medidas más patibularias y militaristas de feroz hípercontrol económico, forma en la cual creen que profundizan el lumpencapitalismo que defienden con fervor juvenil.

A pesar de que su base les ha comprado el delirio de la "guerra económica" y el sabotaje económico permanente y omnímodo, el gobierno sabe que eso es sólo una excusa para tapar los desastres macroeconómicos que promueven las políticas propias del lumpencapitalismo que antes describimos. Por ende, están al tanto de que medidas punitivas contra la "guerra económica" son absolutamente inútiles. La instauración de las mismas no ha hecho sino empeorar los problemas. Por tanto, todo parece indicar que una mayor influencia de China, Rusia y una Cuba mucho más aperturista podrían influir en las decisiones relativas a flexibilizar, romper o suavizar algunas de las vigorosas trabas que el gobierno le coloca a la acumulación de capital privada y pública.

La liberación de varios presos políticos, la flexibilización del control cambiario, la apertura legal para la recepción de remesas, la privatización del icónico Hotel Humboldt y las negociaciones públicas con la federación patronal bancaria (con la aprobación de muchas de sus propuestas, como prorrogar la caótica reconversión monetaria); podrían indicar una moderación significativa en el andar bolivariano. Los cambios en el gabinete ministerial han disminuido de manera llamativa al componente militar y al aclamado "chavismo histórico", éste último proclive a más controles recesivos.

La consolidación de grupos como el de los hermanos Rodríguez (Delcy fue nombrada vicepresidente ejecutiva), el nombramiento del joven liberal de la Universidad de Londres, Calixto Ortega, como presidente del BCV, y la consolidación del grupo de los empresarios árabes Tareck el Aisami y Pérez Abad 5 podría llevarnos a pensar que hay intenciones de profundizar la apertura económica en aras de atraer inversiones extranjeras, renegociar la deuda externa y por todas las cosas tratar de cerrar este año con una caída económica menor al anterior. Si esta tendencia es así, y además logran consolidar negociaciones exitosas con algún factor

5 FEDEINDUSTRIA - Federación de Artesanos, Micros, Pequeñas y Medianas Industrias y Empresas de Venezuela. 
opositor de peso, es bastante probable que el proyecto bolivariano se atornille de nuevo, pero ya con una faz más pragmática. Eso haría mucho más cuesta arriba el trabajo de cualquier oposición y quizás podría traer un alivio económico inmediato, cosa que toda persona sensata desea con juvenil fervor.

\section{REFERENCIAS}

AN: INFLACIÓN de mayo cerró en 110,1\%. El Nacional,11 jun. 2018. Disponible en: <http://www.el-nacional.com/noticias/economia/ inflacion-mayo-cerro-1101_239493>. Fecha de acceso : 25 nov. 2018.

ARMAS, M. La deuda de Pdvsa con el BCV creció 246\% en cinco meses. Cronica Uno, 5 dic. 2016. Disponible en: < http://cronica.uno/deudapdvsa-bcv-crecio-246-cinco-meses/> Fecha de acceso: 25 nov. 2018

BANCO CENTRAL DE VENEZUELA. Disponible en: < http://www.bcv.org. ve/>. Fecha de Acceso: 25 nov. 2018.

CONSEJO NACIONAL ELECTORAL. Resultados electorales. 2018. Disponible en: <http://www.cne.gob.ve/web/estadisticas/index resultados_elecciones.php>. Fecha de acceso: 25 nov. 2018.

RESPO, I. Empresarios reciben hoy de manos del gobierno 3,7 billones de bolívares en crédito. Punto de Corte. 24 enero, 2018. Disponible en: $\quad<$ http://puntodecorte.com/empresarios-reciben-37-billones-encredito/>. Fecha de acceso: 25 nov. 2018.

CURSIO, P. República de Weimar 1923. Últimas Noticias, 25 marzo, 2018. Disponible en:< http://www.ultimasnoticias.com.ve/noticias/opinion/ republica-weimar-1923>. Fecha de acceso: 25 nov. 2018.

DENIZ, R. La industria automotriz de Venezuela retrocede a cotas de 1962. América Económica, 26 enero, 2016. Disponible en: <http:// www.americaeconomica.com/venezuela/22356/automotriz-venezuelaretrocede>. Fecha de acceso: 25 nov. 2018.

ESTAS son las nuevas empresas que recibieron millonarios créditos del Gobierno. Notitotal, 23 marzo, 2017. Disponible en:< http://notitotal. com/2017/03/23/estas-las-nuevas-empresas-recibieron-millonarioscreditos-del-gobierno/>. Fecha de acceso: 25 nov. 2018.

FABRICANTES VENEZOLANOS DE PRODUCTOS AUTOMOTORES. Resumen de ventas de vehículos. Boletín Estadístico FAVENPA, n. 57, oct. 2016. 
GARCÍA BANCHS, Á. (@garciabanchs). “Con la abstención se ha deslegitimado internacionalmente al narcoregimen. Próximo paso deslegitimar internacionalmente a la MUD. Luego nombrar Dictadura republicana (Junta de Gobierno) y finalmente intervenir militarmente Venezuela por meses para tomar el poder $\mathbf{y}$ hacer profilaxia". 26 mayo, 2018, 08h17min.Tweet. Não paginado. Disponible en: <https://twitter.com/garciabanchs/status/1000395595159306240>. Fecha de Acceso : 25 nov. 2018.

GOBERNACIÓN del Zulia: los apagones se deben a que el Sol esta muy cerca de la tierra, un fenómeno llamado "Equinosis". Notiactual, 31 mayo, 2018. Disponible en: <http://www.notiactual.com/gobernacion-del-zulialos-apagones-se-deben-a-que-el-sol-esta-muy-cerca-de-la-tierra-unfenomeno-llamado-equiniosis-video/>. Fecha de acceso: 25 nov. 2018.

INSTITUTO NACIONAL DE ESTADÍSTICAS. Disponible en: <http://www. ine.gov.ve/index.php?option=com_content $\&$ view=category $\&$ id=103\&Item id=0>. Fecha de Acceso: 25 nov. 2018.

KORNBLIHTT, J.; DACHEVSKY, F. Crisis y renta de la tierra petrolera en Venezuela: crítica a la teoría de la Guerra Económica. Revista Cuadernos del Cendes, Caracas, año 34, n. 94, enero-abr. 2017.

MONTES, R. La presión fiscal en América Latina sigue lejos de la media de la OCDE. El País, 11 marzo, 2015. Disponible en: <https://elpais.com/ internacional/2015/03/11/actualidad/1426033896_035583.html>. Fecha de Acceso: 25 nov. 2018.

MORENO, C. Así evolucionó el malandro venezolano. Diario República, 20 jun. 2012. Disponible en:<http://www.diariorepublica.com/reportajes/ as-evolucion-el-malandro-venezolano\#>. Fecha de Acceso: 25 nov. 2018.

MOTTA Domínguez: una vara de bambú se usó para sabotear electricidad. La Voz,19 dic. 2017. Disponible en:< https://diariolavoz.net/2017/12/19/ motta-dominguez-una-vara-bambu-se-uso-sabotear-electricidad/>. Fecha de acceso: 26 nov. 2018.

NEUMAN, W.; TORRES, P. Importadores malversan millones en Venezuela y hunden la economía. NY Times, 5 mayo 2015. Disponible en: <https:// www.nytimes.com/2015/05/06/universal/es/importadores-malversanmillones-en-venezuela-y-hunden-la-economia.html?_r=0>. Fecha de acceso: 25 nov. 2018.

PUCHE, R. TSJ ordenó al CNE excluir tarjeta de la MUD en elecciones presidenciales. Panorama , 25 enero 2018. Disponible en: <https://www. panorama.com.ve/politicayeconomia/TSJ-ordeno-al-CNE-excluir-tarjetade-la-MUD-en-elecciones-presidenciales-20180125-0079.html>. Fecha de acceso: 25 nov. 2018. 
ROMERO, V. R. Maduro ratificó bonos para poseedores del carnet de la Patria que voten el 20M . El Universal, 15 mayo 2018. Disponible en: <http:// www.eluniversal.com: http://www.eluniversal.com/politica/9336/ maduro-volvio-ofrecer-bonos-para-poseedores-carnet-patria-voten $>$. Fecha de acceso: 25 nov. 2018.

SUTHERLAND, M. La ruina del Socialismo no se de debe al socialismo ni a la revolución. Nueva Sociedad, [S.1.], n. 274, p. 142-152, 2018

. ¿Por qué volvió a ganar el chavismo? Revista Nueva Sociedad, oct. 2017a. Disponible en: < http://nuso.org/articulo/por-que-volvioganar-el-chavismo/>. Fecha de acceso: 26 nov. 2018.

Venezuela sin fondo y sin alternativas. Revista Nueva Sociedad , dic. 2017b. Disponible en: < http://nuso.org/articulo/venezuela-sinfondo-y-sin-alternativas/>. Fecha de acceso: 25 dic. 2018.

Crítica a la política económica del socialismo del siglo XXI: apropiación privada de la renta petrolera, política de importaciones y fuga de capitales. Estudios Latinoamericanos, [S.1.], n. 38, p. 39-63, 2016.

¿Progresismo o transición al socialismo? análisis crítico del devenir económico bolivariano. En: CALDERA, Anais López (Comp.). Transición, transformación y rupturas en la Venezuela bolivariana. Caracas: Safita, 2015a. p. 171-208. Disponible en: https://www.rosalux.org.ec/ pdfs/Transicion.pdf>. Fecha de acceso el: 25 nov. 2018.

La enorme escasez de medicinas y la gran estafa en su importación: Farmafraude. Aporrea, 11 marzo 2015b. Disponible en: <https://www. aporrea.org/contraloria/n266676.html>. Fecha de acceso: 25 nov. 2018.

. Aumento del 21.693,21 \% en la importación de carne, caída del consumo y escasez de la misma. Aporrea, 20 agosto 2014. Disponible en: <https:// www.aporrea.org/ddhh/a193540.html>. Fecha de acceso: 25 nov. 2018.

¿QUÉ HACEN en Colombia con los billetes venezolanos? Telesurtv, 12 dic. 2016. Disponible el:< https://www.telesurtv.net/news/Que-hacen-enColombia-con-los-billetes-venezolanos-20161211-0026.html>. Fecha de acceso: 26 nov. 2018.

TERUGGI, M. Venezuela: la economía como arma de guerra. Telesurtv, 2 dic. 2016. Disponible en:< https://www.telesurtv.net/opinion/Venezuelala-economia-como-arma-de-guerra-20161202-0046.html>. Fecha de acceso: 26 nov. 2018.

URDANETA, J. CNE prohíbe a Maduro pago de bonos prometidos a electores. La Verdad, 19 mayo 2018. Disponible en:< http://www.laverdad.com/ politica/141526-cne-prohibe-a-maduro-pago-de-bonos-prometidos-aelectores.html>. Fecha de acceso: 26 nov. 2018. 